\title{
Analysis of comprehensive dental rehabilitation under general anesthesia at a dental hospital in Turkey
}

\author{
Kenan Cantekin*, Salih Doğan, Mustafa Aydınbelge, Dilek Günay Canpolat, Mustafa Denizhan Yıldırım, \\ Serap Avcı \\ Department of Pediatric Dentistry, Faculty of Dentistry, Erciyes University, Kayseri, Turkey
}

\begin{abstract}
The aims of the present study were to describe the characteristics of children receiving comprehensive dental rehabilitation under general anesthesia (DRGA) at a dental hospital in Turkey, and to evaluate dental treatment patterns and waiting times between examination and receiving GA for these children. The authors described the characteristics of children receiving comprehensive DRGA at a dental hospital in Turkey. A total of 441 patients' records were included and were composed of $272(61.7 \%)$ boys and $169(38.3 \%)$ girls. Although most of the children $(159,54.1 \%)$ were aged between 3 and 5 (mean: $5.40 \pm 2.00$ ) years in the healthy children group (Group I), most of the special needs children (Group II) $(85,55.5 \%)$ were aged between 6 and 11 years old (mean: $6.93 \pm 3.13)$. Extreme non-cooperation, dental fear, and an excessive need for treatment were the major reasons for the use of comprehensive dental treatment under GA. The mean waiting times for treatment under GA were significantly shorter in ASA III, ASA IV and disabled children in ASA I and ASA II, compared to physically and mentally fit ASA I and ASA II children.
\end{abstract}

Key words: Dental care, General anesthesia, Special care dentistry

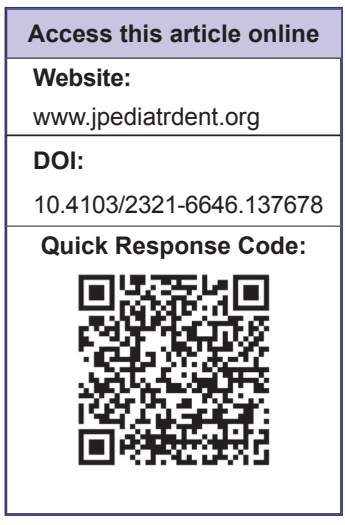

\section{INTRODUCTION}

B ehavioral management techniques play an important role in pediatric dentistry. The techniques can be broadly categorized into two groups:

I. Non-pharmacological, and

2. Pharmacological. Examples of non-pharmacological include tell-show-do, voice control, distraction, coaxing, and immobilization. Pharmacological techniques include either sedation and/or general anesthesia (GA). ${ }^{[1]}$

For most children, dental treatment can be completed in the normal dental setting using any of a number of non-pharmacological behavior management techniques. For a minority of children, however, GA may be required to provide optimal dental treatment. Such groups include children with extreme anxiety, extensive treatment needs, very young age, and/or physical/mental disabilities.
Comprehensive dental rehabilitation under general anesthesia (DRGA) is a treatment option for children. There are several advantages of DRGA, such as its efficiency, convenience, and high-quality restorative and preventive (e.g., fissure sealing) dental treatment in a single appointment. ${ }^{[2]}$

In Turkey, dental care for the pediatric population is free of charge and most children and adolescents receive treatment dental services at dental faculties. In the city of Kayseri, Turkey, DRGA is provided by private dental services for a small number of American Society of Anesthesiologist (ASA) grade I-II patients, whereas all ASA grade III-IV patients are referred to the Dental Hospital of Dental Faculty of Erciyes University.

The Department of Pediatric Dentistry at the Dental Faculty of Erciyes University provides comprehensive dental treatment for children younger than 16 years of age. Most of the patients are treated at the outpatient

\footnotetext{
*Address for correspondence

Dr. Kenan Cantekin, Department of Pediatric Dentistry, Faculty of Dentistry, Erciyes University, Kayseri, Turkey.

E-mail: k_cantekin@hotmail.com
} 
clinic in a non-pharmacologic behavioral management method. In addition, conscious sedation is widely used when treating patients who have difficulties with dental care. Therefore, only those patients whose treatment would otherwise be very difficult are referred for outpatient DRGA. However, a certain percentage of very young individuals, or those suffering extreme anxiety, medical impairment, and mental or physical disabilities, can only be treated at inpatient clinics under GA.

Limited data were available to demonstrate if the treatment needs of these children differ from anxious children and medically/physically or mentally impaired children. In a previous study, Camilleri et al. ${ }^{[3]}$ concluded that the underlying medical disorder in chronically sick children significantly influences the level of dental caries and pattern of dental treatment when this is provided under GA.

We hypothesized that children with chronic medical problem or/and mental/physical disability extensive dental treatment needs that require specific services such as the use of advanced behavior management techniques. Therefore, the aims of the present study were to describe the characteristics of children receiving comprehensive DRGA at a dental hospital in Turkey and to evaluate dental treatment patterns and waiting times between examination and receiving GA for these children.

\section{MATERIALS AND METHODS}

\section{Subjects}

The participants were a consecutive clinical convenience sample of the parents/caregivers of children undergoing DRGA at Gülşah and Mert Tatar's Mouth, Teeth and Jaw Surgery Hospital of Erciyes University, Turkey, at any time during an 8-month period from September 2012 to April 2013. The Ethics Review Board of the Medical Faculty of Erciyes University gave ethical approval for the study.

All patients received a dental and anesthetic assessment in the preoperative period. The dental assessment included a dental and medical history, clinical examination, oral radiographs and appropriate hematological tests. A provisional treatment plan for each patient was formulated and advice on prevention was given to the parents. A consultant anesthesiologist made an assessment of the patient's suitability for GA and commented on any precautions to be taken. On the day of the operation, the treatment plan was finalized and consent was obtained. Most dental treatments were carried out under GA with nasotracheal intubation. Some of patients with limited mouth opening capability or other conditions received orotracheal intubation. All dental treatments were performed by one of three senior pediatric staff dentists.
Premedication with midazolam was permitted for each patient. All subjects received a standardized anesthetic after preoperative acetaminophen $(20 \mathrm{mg} / \mathrm{kg})$ and induction with $8 \%$ sevoflurane and nitrous oxide: oxygen at a concentration of 50:50, followed by propofol $(1-3 \mathrm{mg} / \mathrm{kg})$ to facilitate tracheal intubation.

\section{Data collection}

The data from their personal profiles were retrospectively reviewed, including general history, medical history, dental history, reasons for GA and dental treatment modalities. Treatment under GA was considered necessary if the child needed extensive dental treatment because of severe caries, and showed extreme dental fear and/or behavioral management problems or mental/physical handicap. The children were divided into two groups. Patients included in Group I had neither medical nor physically disability, but suffered from anxiety and dental phobia. Group II was comprised of patients who had a chronic medical problem or/and mental/physical disability. The behavior of all the children was analyzed on the basis of the Frankl scale. Only children with a score of I were accepted for DRGA.

\section{Statistical analyses}

The independent $t$-test was used to compare intergroup differences and the $\chi^{2}$ or Fisher's exact tests were used for categorical variables in demographic and clinical variables. Waiting times were statistically compared using the one-way analysis of variance (ANOVA) and Tukey HSD post hoc test. All statistical analyses were performed using the Statistical Package for the Social Sciences (SPSS), version 15.0 (SPSS Inc., Chicago, IL, USA) for Windows.

\section{RESULTS}

\section{Patients' characteristics}

A total of $44 \mathrm{I}$ patients' records were included and were composed of 272 (6I.7\%) boys and 169 (38.3\%) girls. The mean age at the time of DRGA was 5.9I years $(S D=2.53)$, with a range between 2 and 15 years. Although most of the children $(159,54.1 \%)$ were aged between 3 and 5 (mean: $5.40 \pm 2.00$ ) years in the healthy children group (Group I), most of the special needs children with a medical/physical and/or mental impairment (Group II) (85, $55.5 \%$ ) were aged between 6 and II years old (mean: $6.93 \pm 3.13)$. Group I children were significantly younger than those of Group II $(P<0.00$ I). Only $24(5.4 \%)$ of 44 I children were younger than 3 years and only $16(3.6 \%)$ of the children were older than 12 years of age [Table I].

\section{Distribution of medical conditions}

Of the 44 I cases, 303 (68.7\%), I I 9 (26.9\%), I7 (3.8\%) and $2(0.4 \%)$ patients belonged to ASA I, II, III, and IV, respectively. Detailed patient characteristics are given in Tables 2 and 3. 
Nineteen percent of the patients (84) had a disability and the reasons included mental retardation, as well as physical impairments, such as cerebral palsy, muscular

Table 1: Characteristic of children receiving DRGA

\begin{tabular}{|c|c|c|c|c|c|c|c|c|}
\hline \multirow[t]{4}{*}{ Patients } & & \multicolumn{2}{|c|}{ Total } & \multicolumn{4}{|c|}{$\begin{array}{l}\text { Medical, physical or } \\
\text { mental disability }\end{array}$} & \multirow[t]{4}{*}{$P$} \\
\hline & & & & Gro & up I & $\mathrm{Gr}$ & up II & \\
\hline & & \multicolumn{2}{|c|}{$N=441$} & \multicolumn{2}{|c|}{$N=295$} & \multicolumn{2}{|c|}{$N=146$} & \\
\hline & & $n$ & $\%$ & $n$ & $\%$ & $n$ & $\%$ & \\
\hline \multirow{5}{*}{$\begin{array}{l}\text { Age } \\
\text { (year) }\end{array}$} & $<3$ & 24 & 5.4 & 14 & 4.8 & 10 & 6.8 & 0.24 \\
\hline & $3-5$ & 202 & 45.8 & 159 & 54.1 & 43 & 29.5 & $0.00^{* *}$ \\
\hline & $6-11$ & 199 & 45.1 & 118 & 39.8 & 81 & 55.5 & $0.00^{* *}$ \\
\hline & 12-15 & 16 & 3.6 & 4 & 1.4 & 12 & 8.2 & $0.00^{* *}$ \\
\hline & mean $\pm S D$ & \multicolumn{2}{|c|}{$5.91 \pm 2.53$} & \multicolumn{2}{|c|}{$5.40 \pm 2.00$} & \multicolumn{2}{|c|}{$6.93 \pm 3.13$} & $0.00^{* *}$ \\
\hline
\end{tabular}

Group I: Healthy and severe anxious children, Group II: Medically or physically handicapped children

Table 2: Patients characteristic according to risk index classification of the American Society of Anesthesiology (ASA)

\begin{tabular}{clcc}
\hline & ASA risk index classification & \multicolumn{2}{c}{ No. } \\
\hline Classification & Physical condition of the patient & $n$ & $\%$ \\
\hline 1 & $\begin{array}{l}\text { Patient is a healthy-no } \\
\text { systemic diseases }\end{array}$ & 303 & 68.7 \\
2 & $\begin{array}{l}\text { Patients with mild systemic disease } \\
\text { Serious, non-incapacitating, } \\
\text { systemic disease }\end{array}$ & 119 & 26.9 \\
4 & $\begin{array}{l}\text { Life-threatening, incapacitating } \\
\text { systemic disease } \\
\text { Moribund with death expected within }\end{array}$ & 2 & 0.4 \\
5 & 24 h & & \\
\hline
\end{tabular}

Mangran, 1999 dystrophy, cleft lip and palate, blindness, deafness, and hearing impairment. Twenty-one percent of the patients (93) had medical impairments that included epilepsy, bleeding disorders, blood dyscrasia, and cardiovascular disease, as well as liver transplant children and oncologic children. Overall, $16.8 \%$ of patients (74) had both a medical and a physical impairment.

\section{Levels of dental caries}

The average numbers of teeth with caries were $10.38 \pm$ 3.92 for Group I and $10.65 \pm 4.13$ for Group II. There was no significant difference $(P>0.05)$ in the number of teeth with caries between Groups I and II at any age group.

Treatment procedures and duration of procedure Extractions were provided for 212 (72.1\%) of the healthy group of children (range I-I2) and for 137 (80.1\%) oral intubation group of children (range I-I5). Restorations were provided for 225 of 44 I children (94.1\%) with a mean of 6.1 I (range I-17); III children (25.2\%) had operative (restorative or endodontic) treatment without any extractions being done, and no children $(0 \%)$ had extractions without operative work being provided.

In spite of the extensive treatment needed, the mean number of filled teeth was higher than the mean number of extracted teeth in all the age groups [Table 3]. Although more primary teeth were treated in the 0-6-year-old healthy children than in the special needs children, there was no statistical difference $(P>0.05)$.

Table 3: Caries scores and treatment provided at the time of DRGA

\begin{tabular}{|c|c|c|c|c|c|c|c|c|}
\hline Oral findings and treatment procedures & Age & Group I & SD & Group II & SD & Total & SD & $P$ \\
\hline \multirow[t]{5}{*}{ Caries scores } & $<3$ & 8.21 & 5.96 & 7.70 & 4.73 & 10.47 & 3.98 & 0.82 \\
\hline & $3-5$ & 10.81 & 3.67 & 10.95 & 3.70 & & & 0.82 \\
\hline & $6-11$ & 10.23 & 3.76 & 3.92 & 3.92 & & & 0.17 \\
\hline & $12-15$ & 5.50 & 5.00 & 9.83 & 5.73 & & & 0.20 \\
\hline & Total & 10.38 & 3.92 & 10.65 & 4.13 & & & 0.50 \\
\hline \multirow[t]{5}{*}{ Restorative treatment } & $<3$ & 5.14 & 3.50 & 4.50 & 3.59 & 6.11 & 3.34 & 0.66 \\
\hline & $3-5$ & 6.45 & 3.07 & 6.65 & 2.75 & & & 0.70 \\
\hline & $6-11$ & 5.76 & 3.42 & 6.09 & 3.62 & & & 0.51 \\
\hline & $12-15$ & 2.75 & 3.59 & 7.16 & 4.62 & & & 0.10 \\
\hline & Total & 6.06 & 3.27 & 6.23 & 3.49 & & & 0.61 \\
\hline \multirow[t]{5}{*}{ Pulp therapy } & $<3$ & 2.07 & 2.36 & .90 & 1.66 & 1.68 & 1.95 & 0.19 \\
\hline & $3-5$ & 2.32 & 2.06 & 2.11 & 1.84 & & & 0.54 \\
\hline & $6-11$ & 1.11 & 1.63 & 1.25 & 1.85 & & & 0.58 \\
\hline & $12-15$ & 0.00 & 0.00 & 0.83 & 1.40 & & & 0.26 \\
\hline & Total & 1.80 & 1.99 & 1.45 & 1.84 & & & 0.07 \\
\hline \multirow[t]{5}{*}{ Extraction } & $<3$ & 1.00 & 1.66 & 2.30 & 2.11 & 2.66 & 2.65 & 0.10 \\
\hline & $3-5$ & 2.03 & 2.17 & 2.18 & 2.17 & & & 0.68 \\
\hline & $6-11$ & 3.35 & 2.89 & 3.62 & 3.20 & & & 0.52 \\
\hline & $12-15$ & 2.75 & 1.70 & 1.83 & 1.52 & & & 0.32 \\
\hline & Total & 2.51 & 2.55 & 2.96 & 2.83 & & & 0.09 \\
\hline
\end{tabular}

Group I: Healthy and severe anxious children, Group II: Medically or physically handicapped children 
Of the cases, 16\% could be deemed as "short," lasting up to 30 minutes. The majority, $58 \%$ were intermediate, lasting up to an hour, and $26 \%$ were long, lasting over an hour. Twenty-four children had procedures lasting over 90 minutes. The mean anesthetic times were $64 \pm 26.5$ minutes for non-special needs children and $62 \pm 24.8$ minutes for special needs children. The mean recovery times were $18 \pm 9.2$ minutes for healthy children and $19.3 \pm 9.6$ minutes for special needs children.

\section{Waiting times}

The mean waiting times differed according to medical status and physical/mental disability. Although the post hoc test demonstrated that there were statistically significant differences between healthy children and children with physical/mental disabilities in the ASA I and ASA II groups, such a significant difference was not seen for ASA III children. In addition, healthy children in ASA I and ASA II waited for a fairly long time for dental treatment, and there was no significant difference between ASA I and ASA II healthy children in terms of waiting times $(P>0.05)$. Moreover, there were no significant differences in ASA III and ASA IV children, as well as disabled children in the ASA I and ASA II classification $(P>0.05)$. Detailed information on waiting times is given in Table 4.

\section{DISCUSSION}

Dental treatment performed under GA is a very efficient treatment modality, because it only takes a single appointment and requires little or no cooperation on the part of the patient. It is nevertheless considered the last resort, because GA may pose risks for the patient's overall health. ${ }^{[4,5]}$

The American Academy of Pediatric Dentistry (AAPD) has declared indications for DRGA in children and adolescents as follows:

a. Patients who cannot cooperate due to a lack of psychological or emotional maturity and/or mental, physical, or medical disability; b. Patients for whom local anesthesia is ineffective because of acute infection, anatomical variations, or allergy;

c. Patients who are extremely uncooperative, fearful, anxious, or uncommunicative;

d. Patients who require significant surgical procedures or immediate, comprehensive oral/dental care; and

e. Patients for whom the use of DRGA may protect the developing psyche and/or reduce the medical risks. ${ }^{[6]}$

In the present study, the majority of patients who received dental treatment under GA were healthy children $(66.8 \%)$, and the majority of these were under 5 years of age $(60.0 \%)$. In these healthy children, the greatest difficulty was behavior problems accompanied with severe early childhood caries. Therefore, behavior problems combined with dentistry-related fear and anxiety or lack of cooperation at a young age were the main reason for administering treatment under GA. Several previous studies carried out in different populations present different ratios in terms of the prevalence of healthy children with behavioral problems who were dentally rehabilitated under GA, ranging the prevalence between $40 \%$ and $89.1 \%$. The percentage was higher than that determined by Wong et al. (40\%), ${ }^{[7]}$ Vermeulen et al. (42\%), ${ }^{[8]}$ and Tarjan et al. (49\%). ${ }^{[9]}$ However, Tsai et al., ${ }^{[10]}$ as well as O'Sullivan and Curzon, ${ }^{[1]}$ reported that GA was used for $69.6 \%$ and $76 \%$ of their cases, respectively, due to behavioral problems alone. The highest percentage found in the literature was $89.1 \%$ in a study in Taiwan by Lee et al. ${ }^{[12]}$ The most common reasons reported in several previous studies as to why pediatric dentists' use of GA has increased include: a significant rise in the incidence of severe early childhood caries seen in practice; a growing trend in uncooperative behaviors seen in children; and parents more accepting of GA. In addition, many pediatric dentists noted modern parenting styles to be a significant contributing factor to their increased use of GA. For example, it was reported that parents want a positive experience for their child and do not want to see them cry or fuss during treatment. Parents are concerned about the traumatic emotional experience of

Table 4: Waiting times for treated children according to ASA classification and physically/mentally status

\begin{tabular}{|c|c|c|c|c|c|c|}
\hline \multirow[t]{2}{*}{ ASA Classification } & \multirow[t]{2}{*}{ Physical/mentally status } & \multirow[t]{2}{*}{ No } & \multicolumn{3}{|c|}{ Waiting times (day) } & \multirow[t]{2}{*}{ Post hoc test } \\
\hline & & & Mean (SD) & Min & Max & \\
\hline \multirow[t]{2}{*}{ ASA 1} & Physically/mentally fit & 295 & $154.5(163.1)$ & 11 & 191 & A \\
\hline & Physically/mentally disable & 8 & $6.4(7.2)$ & 1 & 10 & B \\
\hline \multirow[t]{2}{*}{ ASA 2} & Physically fit & 55 & $146.8(152.2)$ & 15 & 188 & A \\
\hline & Physically/mentally disable & 63 & $5.3(6.1)$ & 1 & 11 & B \\
\hline \multirow[t]{2}{*}{ ASA 3} & Physically fit & 4 & $6.2(6.3)$ & 3 & 9 & B \\
\hline & Physically/mentally disable & 13 & $5.1(6.4)$ & 1 & 8 & B \\
\hline \multirow[t]{2}{*}{ ASA 4} & Physically fit & 0 & - & - & - & - \\
\hline & Physically/mentally disable & 2 & 5.5 & 4 & 7 & B \\
\hline Total & & 441 & $117.6(127)$ & 1 & 191 & $P<0.001$ \\
\hline
\end{tabular}

* According to post-hoc multi-compared test same letter stated that there was no significant difference 
the dental visit. Thus, more parents are less tolerant of the various behavior management techniques (i.e., passive immobilization) outlined in the AAPD behavior guidance clinical guidelines. ${ }^{[3,7,8,10-14]}$

The mean caries scores of healthy and medically/physically disabled children in the 3-5 age groups (10.8I and 10.95 respectively) was much higher than the average caries scores in Turkey, which was reported as 5.82 at 5 years of age. ${ }^{[15]}$ Nevertheless, the mean caries scores found in our study was lower than the findings of Tsai et al., ${ }^{[10]}$ who found that the mean number of decayed teeth per patient treated under GA was 15.2 in Taiwanese children.

In the present study, we demonstrated that there was a trend towards conducting dental procedures under GA where most of the healthy children were under 5 years of age. On the contrary, most of the children with a disability or who were chronically ill were older than 6 years of age. Harrison et al. ${ }^{[13]}$ suggested that parents of chronically sick children are usually aware of the need for dental treatment, but preoccupation with immediate medical needs frequently causes considerable delays in seeking dental treatment. Similarly, Haubek et al. ${ }^{[14]}$ reported that special needs children were older than healthy children and they suggested two possible explanations for this pattern. The first is that children with special needs have, in their daily life, more severe and complicated healthcare needs than caries, which may lead to dental treatment receiving a lower priority and consequently a later referral. Second, the special needs children often attend specialized schools and daycare centers with specialized personnel who are aware of the importance of preventive dental care in terms of tooth brushing, non-sugary diets, et cetera. Therefore, special needs children do not develop a need for treatment until they are older. On the contrary, Cantekin et al. ${ }^{[16]}$ compared the formation of dental caries in healthy children and children with chronic medical illness and disclosed that there is a significant difference between healthy children and children who are medically compromised in terms of the development of caries, and in meeting the need for dental treatment. They suggested that there are at least three reasons for the lower percentage of restorative treatment in children who are medically compromised. First, parents of children who are medically compromised are not sufficiently informed about the importance of oral hygiene and the adverse effects of dental disease on the quality of life. Second, the practicing (general) dentists are reluctant to treat those children. Third, pediatricians do not provide adequate information to families of children who are medically compromised about the importance of oral care. On the other hand, Worthen and Mueller ${ }^{[17]}$ suggested that comprehensive dental treatment under GA for children at high risk of caries be delayed until the eruption of the primary second molars to reduce the need for a second such procedure.
In recently published guidelines regarding the use of GA in pediatric dentistry, the Royal College of Surgeons of England propose that pediatric dentists should move from extraction toward more comprehensive and conservative treatment in DRGA procedures. ${ }^{[18]}$ When considering the treatment pattern in the present study population, there were more restored than extracted teeth, indicating our hospital treatment process was a comprehensive, conservative approach characterized by a predominance of fillings and pulp therapy. Regarding treatment approach, there were no significant differences for restorations, pulp therapy, and extraction between the group of healthy subjects and the group of patients with specific care needs $(P>0.05)$. Similar studies carried out in different countries reported dental treatment provisions and the patients' characteristics. Comprehensive DRGA has been reported earlier in many European countries, ${ }^{[8,9,13,19,20]}$ North America, ${ }^{[21]}$ the Middle East, ${ }^{[22-24]}$ Asia, ${ }^{[25]}$ and New Zealand. ${ }^{[26]}$ On the contrary, some previous studies from Australia and England reported that DRGA is used dominantly for extractions in both children and adults ${ }^{[27-29]}$ although a move towards comprehensive DRGA care has also been made in the United Kingdom (UK) since the publication of the Royal College of Surgeons' guidelines. On the other hand, Camilleri et al. ${ }^{[3]}$ compared the level of dental disease and the pattern of dental treatment under GA for ASA I and II children and ASA III and IV children in two hospitals in England. They found that ASA III and IV children have significantly lower levels of dental caries than ASA I and II children, and received a higher level of preventive and restorative care. Therefore, the authors suggest that it is not true that medically compromised children receiving dental treatment under GA have more extractions and fewer restorations than ASA I and II children undergoing similar procedures.

Though dental treatment procedures for both groups in the present study were similar, no difference between the groups was found in the duration of dental procedures under GA. The DRGA guidelines by the Royal College of Surgeons in England propose that anesthetic duration should not exceed 40 minutes for dental rehabilitation in children. In this study, however, the mean number of dental procedures per patient was 10.4 with the mean treatment duration slightly more than 60 minutes. In accordance with our findings, most of the previous studies reported longer duration periods for full-mouth treatment than proposed in the guidelines. Ventura et al. ${ }^{[30]}$ reported that up to 3 hours may be required for full-mouth rehabilitation under GA. Similarly, Tsai et al. ${ }^{[10]}$ carried out an average of 21.7 dental treatment procedures on 184 Taiwanese children under GA and reported that these procedures were completed between 2.4 and 3.8 hours. 
The mean waiting times from referral to DRGA was slightly less than 4 months. This waiting period, however, ranged from I day to 191 days according to the patient's medical priority, pain because of large untreated cavities, and dental abscess or cellulites which may be result in facial asymmetry, sepsis, meningitis, or Ludwig angina. In the previous studies, waiting times ranged from I to 9 months. Some of these studies reported mean waiting times of four months or less conducted in England (2.5-3 months), ${ }^{[31]}$ Australia (2-3 months), ${ }^{[32]}$ and the United States (I-2.5 months), ${ }^{[3]}$ but some other studies reported longer waiting times from Denmark (4.3 months) $)^{[14]}$ and England (4.9 months and 4-9 months), respectively. ${ }^{[7,11]}$

Our data based on the pediatric Dental Service of the Dental Faculty of Erciyes University reflected that, out of a total of approximately I,200,000 Kayseri residents, about 12,000 pediatric patients less than 16 years of age were treated in the service during an 8-month period. Only $3.6 \%$ (44I) of those treated were DRGA patients, indicating that DRGA is used as a last resort and only when certain strict criteria have been fulfilled.

\section{CONCLUSION}

I. Extreme non-cooperation, dental fear, and an excessive need for treatment were the major reasons for the use of comprehensive dental treatment under general anesthesia.

2. All children admitted for treatment had high levels of dental caries.

3. The mean waiting times for treatment under GA were significantly shorter in ASA III, ASA IV and disabled children in ASA I and ASA II, compared to physically and mentally fit ASA I and ASA II children.

4. Although the mean age of patients with a chronic illness and/or disability was higher than healthy children, patients with a chronic illness and/or disability had a similar average level of dental caries. In addition, these children received similar restorations, pulpal treatments, and underwent similar extractions as the healthy children.

5. There was an overall predominance of operative treatments in both groups of children, which reflected that treatment under GA is more conservative.

\section{REFERENCES}

1. Mayeda C, Wilson S. Complications within the first 24 hours after dental rehabilitation under general anesthesia. Pediatr Dent 2009;31:513-9.

2. Thomson WM, Malden PE. Assessing change in the family impact of caries in young children after treatment under general anaesthesia. Acta Odontol Scand 2011;69:257-62.

3. Camilleri A, Roberts G, Ashley P, Scheer B. Analysis of paediatric dental care provided under general anaesthesia and levels of dental disease in two hospitals. Br Dent J 2004;196:219-23.
4. Sun L. Early childhood general anaesthesia exposure and neurocognitive development. Br J Anaesth 2010;105(Suppl 1):i61-8.

5. Stratmann G. Review article: Neurotoxicity of anesthetic drugs in the developing brain. Anesth Analg 2011;113:1170-9.

6. Affairs AAoPDCoC. Guideline on management of dental patients with special health care needs. Pediatr Dent 2008;30:107-11.

7. Wong FS, Fearne JM, Brook AH. Planning future general anaesthetic services in paediatric dentistry on the basis of evidence: An analysis of children treated in the Day Stay Centre at the Royal Hospitals NHS Trust, London, between 1985-95. Int Dent J 1997;47:285-92.

8. Vermeulen M, Vinckier F, Vandenbroucke J. Dental general anesthesia: Clinical characteristics of 933 patients. ASDC J Dent Child 1991;58:27-30.

9. Tarjan I, Mikecz G, Denes J. General anaesthesia of out-patients in pedodontics. J Int Assoc Dent Child 1990;20:59-61.

10. Tsai CL, Tsai YL, Lin YT. A retrospective study of dental treatment under general anesthesia of children with or without a chronic illness and/or a disability. Chang Gung Med J 2006;29:412-8.

11. O'Sullivan EA, Curzon ME. The efficacy of comprehensive dental care for children under general anesthesia. Br Dent J 1991;171:56-8.

12. Lee PY, Chou MY, Chen YL, Chen LP, Wang CJ, Huang WH. Comprehensive dental treatment under general anesthesia in healthy and disabled children. Chang Gung Med J 2009;32:636-42.

13. Harrison MG, Roberts GJ. Comprehensive dental treatment of healthy and chronically sick children under intubation general anaesthesia during a 5-year period. Br Dent J 1998;184:503-6.

14. Haubek D, Fuglsang M, Poulsen S, Rolling I. Dental treatment of children referred to general anaesthesia--association with country of origin and medical status. Int J Paediatr Dent 2006;16:239-46.

15. Kuvvetli SS, Cildir SK, Ergeneli S, Sandalli N. Prevalence of noncavitated and cavitated carious lesions in a group of 5-year-old Turkish children in Kadikoy, Istanbul. J Dent Child (Chic) 2008;75:158-63.

16. Cantekin K, Yilmaz Y, Cantekin I, Torun Y. Comprehensive dental evaluation of children with congenital or acquired heart diseaseCORRIGENDUM. Cardiol Young 2013;23:705-10.

17. Worthen TB, Mueller W. Implications of parental compliance on decision making in care provided using general anesthesia in a low-income population. ASDC J Dent Child 2000;67:197-9,161.

18. Davies C, Harrison M, G R. UK national clinical guidelines in paediatric dentistry: Guideline for the use of general anaesthesia (GA) in paediatric dentistry. London: Royal College of Surgeons of England; 2008.

19. Grytten J, Holst D, Dyrberg L, Faehn O. Some characteristics of patients given dental treatment under general anesthesia. Acta Odontol Scand 1989;47:1-5.

20. Vinckier F, Gizani S, Declerck D. Comprehensive dental care for children with rampant caries under general anaesthesia. Int J Paediatr Dent 2001;11:25-32.

21. Loyola-Rodriguez JP, Zavala-Alonso V, Gonzalez-Alvarez CL, Juarez-Lopez LA, Patino-Marin N, Gonzalez CD. Dental treatment under general anesthesia in healthy and medically compromised developmentally disabled children: A comparative study. J Clin Pediatr Dent 2009;34:177-82.

22. Peretz B, Spierer A, Spierer S, Rakocz M. Dental treatment of patients with systemic diseases compared to patients with developmental disabilities under general anesthesia. Spec Care Dentist 2012;32:21-5.

23. Ibricevic $\mathrm{H}, \mathrm{Al}-J a m e \mathrm{Q}$, Honkala S. Pediatric dental procedures under general anesthesia at the Amiri Hospital in Kuwait. J Clin Pediatr Dent 2001;25:337-42.

24. Jamjoom MM, al-Malik MI, Holt RD, el-Nassry A. Dental treatment under general anaesthesia at a hospital in Jeddah, Saudi Arabia. Int J Paediatr Dent 2001;11:110-6.

25. Kwok-Tung L, King NM. Retrospective audit of caries management techniques for children under general anesthesia over an 18-year period. J Clin Pediatr Dent 2006;31:58-62.

26. Drummond BK, Davidson LE, Williams SM, Moffat SM, Ayers KM. Outcomes two, three and four years after comprehensive care under general anaesthesia. N Z Dent J 2004;100:32-7. 
27. Jamieson LM, Roberts-Thomson KF. Dental general anaesthetic trends among Australian children. BMC Oral Health 2006;6:16.

28. Jamieson LM, Roberts-Thomson KF. Indigenous children and receipt of hospital dental care in Australia. Int J Paediatr Dent 2006;16:327-34.

29. Moles DR, Ashley P. Hospital admissions for dental care in children: England 1997-2006. Br Dent J 2009;206:E14;discussion 378-9.

30. Ventura E, Levy E, Friedman M, Gat H. General anesthesia for complete oral rehabilitation in children. ASDC J Dent Child 1981;48:33-5.

31. Mason C, Holt RD, Rule DC. The changing pattern of day-care treatment for children in a London dental teaching hospital. Br Dent J 1995;179: $136-40$.
32. Alcaino E, Kilpatrick NM, Smith ED. Utilization of day stay general anaesthesia for the provision of dental treatment to children in New South Wales, Australia. Int J Paediatr Dent 2000;10:206-12.

33. Lewis CW, Nowak AJ. Stretching the safety net too far waiting times for dental treatment. Pediatr Dent 2002;24:6-10.

How to cite this article: Cantekin $\mathrm{K}$, Dogan $\mathrm{S}$, Aydinbelge $\mathrm{M}$, Canpolat DG, Yildirim MD, Avci S. Analysis of comprehensive dental rehabilitation under general anesthesia at a dental hospital in Turkey. J Pediatr Dent 2014;2:49-55.

Source of Support: Nil. Conflict of Interest: None declared. 